
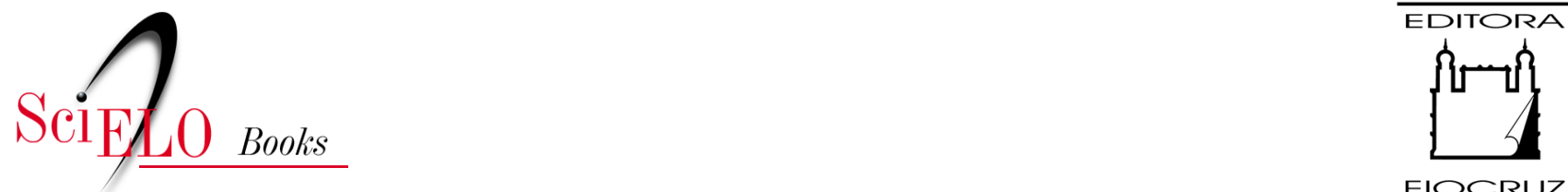

FIOCRUZ

\title{
7 - Aprendizados gerados pela experiência e potencialidades de adaptação para outros contextos
}

\author{
Luiza Garnelo \\ Sully de Souza Sampaio \\ Ana Lúcia Pontes
}

\section{SciELO Books / SciELO Livros / SciELO Libros}

GARNELO, L., SAMPAIO, S.S., and PONTES, A.L. Aprendizados gerados pela experiência e potencialidades de adaptação para outros contextos. In: Atenção diferenciada: a formação técnica de agentes indígenas de saúde do Alto Rio Negro [online]. Rio de Janeiro: Editora FIOCRUZ, 2019, pp. 135-153. Fazer saúde collection. ISBN: 978-65-5708-011-5.

https://doi.org/10.7476/9786557080115.0008.

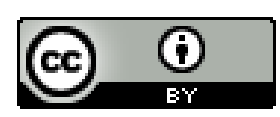

All the contents of this work, except where otherwise noted, is licensed under a Creative Commons Attribution $\underline{4.0 \text { International license. }}$

Todo o conteúdo deste trabalho, exceto quando houver ressalva, é publicado sob a licença Creative Commons Atribição 4.0.

Todo el contenido de esta obra, excepto donde se indique lo contrario, está bajo licencia de la licencia Creative Commons Reconocimento 4.0. 


\section{Aprendizados gerados pela experiência e potencialidades de adaptação para outros contextos}

A realização do CTACIS na região do Alto Rio Negro propiciou um rico aprendizado docente-discente no âmbito do próprio curso, e com potencial para aplicação em outros contextos no Sasi e até mesmo na rede de APS voltada para o atendimento de não indígenas.

Nessa trajetória, o primeiro ponto a ser destacado foi o intenso e contínuo envolvimento do movimento indígena, representado naquela região pela FOIRN, cujo protagonismo político se exerceu não apenas na demanda que desencadeou a iniciativa, mas também ao longo de todo o processo formador, em que a federação teve papel crucial de apoio ao curso nos momentos em que enfrentou sérias ameaças de interrupção. A constância das lideranças na defesa do curso contrabalançou a instabilidade gerada pelas recorrentes mudanças de profissionais e dirigentes do DSEI e da própria Sesai. A cada mudança de pessoal, a coordenação do CTACIS precisava promover rodadas de reuniões para explicar ao(s) novo(s) integrante(s) a origem e as finalidades do curso, os modos de funcionamento e outros dados que sensibilizassem os recém-chegados para a importância da iniciativa.

Muito importantes também foram a paciente atuação de lideranças indígenas como docentes do curso, recuperando a história não escrita das lutas étnico-políticas travadas pelo movimento indígena rio-negrino nos últimos trinta anos, bem como a atuação dos especialistas em medicinas tradicionais que, repetidas vezes, trabalharam com os AIS. Entendemos que uma relação sólida com lideranças de movimentos sociais é condição estratégica para uma bem-sucedida replicação da experiência.

Frequentemente se fala sobre a dificuldade de realizar, articuladamente, a elevação da escolaridade formal e a profissionalização em nível médio. Nossa experiência nesse âmbito foi positiva, seja por parte dos gestores da educação, em particular dos encarregados da educação escolar indígena que demonstraram forte interesse na iniciativa, seja por parte 
dos estudantes que deram o melhor de si para lidar com múltiplas demandas e atender aos requisitos no curso. Consideramos que a aproximação do campo da saúde indígena com o da educação indígena foi fundamental para o exercício da sensibilidade cultural no processo formador, devendo ser estimulada em iniciativas similares.

A construção curricular do curso também deve ser objeto de reflexão nesta avaliação final. A eleição de temáticas como modelo de atenção orientado para vigilância em saúde e organização/reorganização do processo de trabalho em saúde para a mesma finalidade resultou numa abordagem que explorou a articulação teórico-prática entre vigilância e serviços de saúde. Este enfoque aportou inovações na maneira de desenvolver conteúdos curriculares que contribuíssem para o reordenamento do processo de trabalho e para a superação do modelo biomédico, orientado para a demanda espontânea. Dentre os conteúdos que orientaram a reorganização do trabalho do AIS destacam-se o entendimento das condições de vida e a detecção de necessidades de saúde no território. Com essa perspectiva mais ampla, foi possível refletir sobre modos de vida, aí incluída a concepção indígena de bem viver, e explorar as interrelações com a sustentabilidade ambiental. Trata-se de uma questão crucial para as famílias rio-negrinas cujas principais fontes de subsistência dependem da preservação de seus territórios e da vitalidade dos conhecimentos tradicionais, pois estes permeiam a gestão das relações com a natureza e as técnicas de extração de recursos para a subsistência, bem como minimizam os danos (materiais e simbólicos) decorrentes da predação humana.

O cruzamento entre o conhecimento dos modos indígenas específicos de viver em território e as ações de vigilância a serem desenvolvidas pelo AIS talvez seja o aspecto de mais difícil adaptação dos conteúdos do curso para outras realidades. Para desenvolvêla adequadamente, seria necessário ancorar o processo formador em conhecimento antropológico prévio sobre os grupos étnicos participantes no curso. Entretanto, no Brasil, não se dispõe de acervo próprio para todas as etnias atendidas pelo Sasi. Tais obstáculos podem ser minimizados mediante a seleção de docentes e supervisores com ampla experiência pedagógica, vivência na relação ensino-serviço e sensibilidade às demandas e necessidades de saúde dos grupos envolvidos. Importante também é o conhecimento sobre as características do exercício do poder político intra e interétnico nos locais de realização dos cursos.

Porém, mesmo na ausência de antropólogos com conhecimento das culturas nativas envolvidas na iniciativa, a opção da estratégia ensino pela pesquisa pode suprir, em grande medida, a necessária produção de informações desenvolvidas pelos próprios estudantes. É essencial que pelo menos um membro da equipe tenha experiência com pesquisa aplicada ao ensino, e que seja capaz de sistematizar as informações obtidas por essa via e de convertê-las em conteúdos significativos de aprendizado. 
No curso ministrado no Alto Rio Negro, destacam-se, como exemplo de abordagens apoiadas no ensino pela pesquisa, os conteúdos curriculares de saúde da mulher e da criança, cujo desenvolvimento se apoiou fortemente na ideia nativa de fases ou ciclos de vida. Sugere-se, nesses casos, vigilância atenta aos riscos e armadilhas advindos de categorias biomédicas, tão arraigadas em nosso senso comum que seu caráter etnocêntrico costuma passar desapercebido. Como exemplos, podemos citar, entre outras, noções problematizadas ao longo dos capítulos anteriores, tais como, faixa etária, infância, corporalidade. O levantamento do entendimento nativo dessas categorias pode ser feito através do ensino pela pesquisa, prática pedagógica com potencial para guiar a proposta de organização de um cuidado não limitado pelo molde biomédico.

Essa estratégia propiciou a organização de um amplo acervo de materiais que versam sobre os territórios, modos de vida e saberes indígenas que foram retomados e reaproveitados em diversos momentos do curso. A análise minuciosa desse acervo ainda está por ser feita, devendo ser objeto de estudos futuros.

O corpo docente fez um grande esforço para construir, com os estudantes, um conjunto de atribuições para os AIS, orientadas pelo modelo de vigilância em saúde e trabalhadas em cada eixo temático do curso. O leitor talvez se ressinta da falta de um delineamento equivalente para os outros profissionais da equipe. Cabe esclarecer, portanto, que a apresentação de um conjunto de atribuições em alguns capítulos, e em particular no detalhado roteiro orientador da realização da visita domiciliar, não expressa a ideia de isolamento na atuação do AIS. Pelo contrário, a iniciativa buscou ofertar um guia de ações específicas a serem desenvolvidas por um membro da equipe cujo perfil de atribuições permanece insuficientemente delineado, não apenas no Sasi, mas no SUS como um todo. Além disso, o foco do curso se dirigia aos AIS, não cabendo extrapolar a proposta de redesenho de atribuições para outros profissionais.

Ainda assim, a harmonização entre as atribuições de diversos profissionais que atuam nas Emsis (AIS e demais membros) se fez visível em diversos momentos. Está exemplificada no fluxograma de organização das consultas de pré-natal, em que as tarefas e a interatuação de todos os membros da Emsis estão claramente apresentadas, mas sem abrir mão de demonstrar atividades específicas a serem desenvolvidas pelo AIS (conferir capítulo 6).

Os coordenadores do curso, em decorrência da sua experiência prévia, já tinham clareza de que as potencialidades do trabalho do AIS eram subaproveitadas no trabalho cotidiano das equipes do DSEI. Esse foi um dos fatos que gerou a demanda do curso pelas lideranças indígenas. A percepção de que aos AIS só eram delegadas tarefas subalternas e braçais guiou a luta da FOIRN pela elevação da escolaridade e formação profissional 
em nível médio, bem como pela reivindicação de um espaço próprio de atuação para o membro indígena da Emsi, na busca de propor um conjunto de atividades especificas do trabalho do AIS, sem perder de vista o lugar que esse ocupa nas linhas de cuidado instituídas pelo DSEl e as características de sua inserção na comunidade.

Outro aspecto a ser considerado é que na Amazônia, diferentemente de outras realidades, os AIS representam a primeira - e por vezes a única - linha de frente na oferta de cuidados de APS. Além disso, a carência de rede de serviços os obriga ao manejo de situações de emergência, que, ao ocorrerem em lugares remotos, obrigam os agentes a assumir um papel estratégico na identificação de sinais de riscos que ameaçam a vida e a tomar decisões sobre encaminhar, ou não, um doente para um serviço de saúde localizado fora da aldeia. Em que pese esse papel imposto pelas características do rural amazônico, poucos eram os AIS preparados para identificar esses sintomas e efetuar a tomada de decisão necessária para cada caso.

Não se trata de atribuir aos AIS o papel de médico socorrista, mas de reconhecer que as carências assistenciais vigentes na região compelem os profissionais a realizar ações que extrapolam o nível de cuidados típicos de APS. Conhecedores dessa realidade e das difíceis condições de acesso às aldeias indígenas, entendemos que o curso deveria incluir um determinado número de horas para capacitar os AIS a identificar situações que ameaçam a vida e para auxiliá-los na adoção de parâmetros para a tomada de decisões.

O envolvimento dos profissionais das Emsis foi sempre um pressuposto orientador do processo formativo, seja pelo desejo de garantir-lhes a participação, seja pelo propósito de sensibilizá-los para a importância do modelo assistencial calcado na vigilância em saúde. Tínhamos a certeza, também, de que os AIS não poderiam desenvolver as novas tarefas a contento se não contassem com o apoio e a orientação dos outros profissionais, em particular dos enfermeiros. Tal propósito mostrou-se um desafio que poucas vezes foi satisfatoriamente superado ao longo do curso, dada a dificuldade de garantir a participação continuada dos profissionais do DSEI nas atividades de cada polo formador. Entre as razões para essa descontinuidade, constataram-se a desmotivação dos profissionais com o trabalho, o desinteresse por atividades formativas e, principalmente, o descumprimento do calendário de viagens de atendimento em área indígena e a elevada rotatividade dos profissionais e gestores do DSEI. Os problemas relativos à falta de motivação eram facilmente solucionados após alguns dias de frequência ao curso; ali o entusiasmo de estudantes e professores contagiava a todos. Os demais, inerentes à organização do trabalho no DSEI, se converteram em obstáculos a serem contornados a cada fase do processo formativo, e, sobre eles, não tínhamos qualquer governabilidade. 
Também tivemos pouco sucesso no enfrentamento da resistência de muitos profissionais em rever suas rotinas de trabalho para adicionar atividades como reconhecimento do território, educação em saúde e programação da demanda, entre outras. A capacitação dos AIS para essas tarefas passou a gerar demandas similares para os outros profissionais; alguns responderam positivamente, ao passo que outros persistiram mantendo a prioridade dada ao atendimento por demanda espontânea. Paralelamente, observamos limitada aceitação da ampliação do escopo das atividades dos AIS por parte dos profissionais que atuavam no DSEI, mas não participavam do curso. Aqueles que colaboraram com a iniciativa aprofundaram vínculos com os AIS e ampliaram sua compreensão sobre a relevância desse novo perfil de atuação, reconhecendo sua potencialidade em contribuir no aprimoramento do trabalho da equipe como um todo. Porém, os que nunca haviam participado mantiveram atitudes reticentes e defensivas, sendo perceptível, em alguns casos, a enunciação de juízos depreciativos sobre os AIS e o entendimento de que suas novas atribuições representavam ameaças ao trabalho rotineiro instituído. Em consequência, houve relatos de que alguns integrantes da equipe multiprofissional desestimulavam, ou até mesmo impediam, a execução das novas tarefas dos AIS, pactuadas no curso.

Tais relatos reafirmam o caráter político das linhas guia do projeto pedagógico do curso, gerando contradições com o modelo biomédico de atuação, predominante no DSEI. Trata-se de nível de discordância mais profundo que a mera recusa ao processo de qualificação do trabalho dos AIS que revela apego a rotinas pouco compromissadas com as características da APS e dificultam a conversão em direção a um modelo assistencial pautado pelas necessidades de saúde no território. Tal problema não é específico do Sasi. Trata-se, pelo contrário, de um entrave no processo de gestão da APS que perpassa boa parte da rede assistencial.

Reafirma-se, assim, a importância do envolvimento dos outros membros da equipe no processo formador, visto que as atitudes negativas provieram justamente dos que não aceitaram participar das atividades do curso. É plausível supor que situações similares sejam encontradas em outros locais e contextos, uma vez que as assimetrias e hierarquias entre categorias profissionais não se limitam aos DSEls ou à rede de APS encontrando sua gênese na própria estrutura de classes da sociedade.

A adoção de pedagogias ativas consorciadas às múltiplas estratégias de ensinoaprendizado priorizou as atividades práticas e a atuação docente dos sábios indígenas, mostrando-se um caminho produtivo que efetivou, na prática, uma das ambições interculturais do curso: a de equilibrar de modo harmônico o aporte de saberes científicos e indígenas no processo formador. Além de propiciar uma via de escape do monopólio 
exercido pelo conhecimento biomédico nos cursos anteriores ofertados ao AIS, tal escolha também expressa o compromisso político de trazer para primeiro plano, e como parte integrante das atribuições do AIS, a interlocução não apenas com especialistas tradicionais de cura, mas também com as pessoas comuns das aldeias, reconhecidas como protagonistas e detentoras de conhecimento e de meios de produzir saúde. O uso intensivo das dramatizações foi bastante importante para identificar as expectativas dos AIS acerca do seu papel na equipe e na comunidade. Essa prática também produziu relatos tão vívidos e sistemáticos quanto os obtidos por etnografias e possibilitou descortinar um panorama da atuação cotidiana dos profissionais não indígenas, marcada, não raro, por juízos de valor carregados de etnocentrismo.

A produção textual e gráfica de materiais educativos não só cumpriu finalidades inerentes à educação em saúde dirigida à comunidade, mas também operou como estratégia de revisão de conteúdos e de avaliação formativa do aprendizado, conduzindo os estudantes à produção de novos significados aos materiais educativos, à medida que os traduziam do português para as línguas indígenas e vice-versa. Muito mais que uma transposição de termos de uma língua para outra, trata-se de uma reconstrução, pautada no primado do local, de saberes, conceitos, significados e estratégias de ação que visam a adequá-los às condições e modos de vida nos cenários de atuação dos AIS.

Um avanço derivado da tradução de elementos de sentido de uma cultura para outra é o reconhecimento da importância de incluir diferentes pontos de vista na priorização das necessidades e problemas de saúde. Em que pese a importância da informação epidemiológica para orientar essa tomada de decisão em saúde, as reuniões comunitárias deixaram bem claro que as necessidades sentidas podem ser muito distintas das que são consideradas como prioritárias pelas políticas públicas e pela atuação das equipes de saúde. A valorização do diálogo com a população atendida permitiu evidenciar que as mulheres indígenas tinham como demanda principal algum tipo de solução para o crescente acúmulo de lixo nas aldeias e para suas dores de ordem musculoesqueléticas decorrentes das duras condições do trabalho na roça. Para a primeira reivindicação, o DSEI não dispunha de qualquer proposta, encaminhamento ou diálogo com as comunidades para equacionar o problema gerado pela ampliação do consumo de produtos industrializados. A segunda demanda - muito relevante para combater a desnutrição, já que é o trabalho feminino que provê a maior parte do alimento consumido na família - sequer era reconhecida pelos profissionais como problema de saúde digno de constar nas metas e prioridades de ação nos planos distritais. Essas dores não eram tratadas como um problema de saúde do trabalhador rural, e sua abordagem se limitava à prescrição de sintomáticos, induzindo ao uso abusivo de anti-inflamatórios. 
A exploração minuciosa dos instrumentos de registro e de acompanhamento utilizados pela equipe de saúde possibilitou compreender que não se tratavam de meros entraves burocráticos. Foi possível avaliar a importância desses instrumentos para ordenar as atribuições e rotinas de atuação dos profissionais da saúde e para entender a lógica organizativa do cuidado, bem como a gravidade dos problemas acarretados pelo mau uso deles. Cabe destacar a reação - entre surpresa e indignação - dos estudantes ao perceberem inúmeras falhas de registro e de realização de ações do pré-natal, depois que aprenderam a revisar os cartões/cadernetas de suas esposas e irmãs gestantes. De modo similar, a apresentação detalhada e objetiva da técnica de coleta de exame de Papanicolau mostrou que, por vezes, colocar a explicação biomédica em primeiro plano é a melhor via para entender as razões pelas quais as mulheres devem realizar esse exame. O vídeo apresentado sobre o tema deu concretude a um assunto nebuloso para os AIS, uma vez que sua condição masculina dificultava-lhes imaginar de que forma o exame preventivo do câncer de colo de útero era realizado, o que tornava pouco convincente sua tentativa de motivar as mulheres a aderirem ao procedimento.

Antes de finalizarmos, faz-se necessário problematizar as tensões surgidas em torno da elevação da escolaridade dos AIS como consequência do curso. Essa foi sem dúvida a principal fonte de insatisfação de gestores que atuavam na Sesai, à época em que foi realizado. Do início ao fim da iniciativa, o posicionamento de gestores do Sasi evidenciou o interesse pelo caráter inovador e culturalmente sensível da proposta, desde que consistisse em mera atualização. Entretanto, se opunham ao reconhecimento dos AIS como técnicos de nível médio, pois alegavam falta de provimento desse cargo no seu quadro de alocação de pessoal terceirizado.

Tal argumento é usado também por outros gestores do SUS contrários ao reconhecimento da elevação da escolaridade de seus contratados, pois priorizam a necessidade de reduzir gastos com pessoal. Esse é um impasse que pode obstaculizar a replicação da experiência em outros DSEls ou em secretarias municipais de Saúde, dada a conhecida restrição dos gestores em onerar as folhas de pagamento com o reenquadramento dos AIS como profissionais de nível médio.

Apesar do posicionamento negativo dos dirigentes sobre o tema, optamos por persistir e efetivar a elevação da escolaridade até a conclusão do nível médio com formação profissionalizante. As razões para fazê-lo foram essencialmente políticas: em primeiro lugar, atendíamos a uma reivindicação das lideranças indígenas, comprometidas com a melhoria das condições de vida dos seus povos e sabedoras que a escolarização é uma das vias preferenciais para alcançar essa meta. Também tínhamos clareza de que a ambição do projeto em potencializar a implantação das ações de vigilância no 
escopo de atividades dos AIS demandaria um processo pedagógico longo e complexo que exigiria proficiência em campos de saberes mais aprofundados que não poderiam ser obtidos apenas nas primeiras séries escolares. Na ausência de elevação concomitante da escolaridade, o maior aproveitamento do curso só poderia ocorrer entre os estudantes que já tivessem concluído ensino fundamental e médio, ou seja, a minoria. Estávamos bem conscientes do valor que os povos do Alto Rio Negro atribuem à educação e do quanto ela representava para a autoestima dos AIS. Somente os que testemunharam a emoção dos nossos estudantes na cerimônia de formatura puderam compreender quão significativo foi, para todos nós, ter logrado finalizar a experiência com sucesso.

Também tínhamos clareza de queocampo da saúdeéum cenário marcado pela hierarquia de profissões e que a baixa escolaridade dos AIS era uma das fontes de desvalorização profissional aos olhos dos outros integrantes das equipes multidisciplinares. A luta por respeitabilidade profissional não se restringe a elevar a escolaridade, mas certamente passa por ela. Consideramos mais do que justo que o profissional que permanece nas comunidades ao longo de todo o ano receba remuneração condizente com sua atuação no Sasi. Também consideramos que os dirigentes comprometidos com a melhoria da qualidade da atenção devem reconhecer o saldo positivo que a qualificação dessa força de trabalho pode representar na efetividade das ações de APS sob sua responsabilidade.

Por razões como essas persistimos em levar a experiência até o desfecho originalmente programado. Temos, porém, ciência das implicações subjacentes a essa questão. Por isso, organizamos a implementação dos conteúdos do CTACIS de modo a permitir que estes possam ser recortados e executados em frações menores, compatíveis com atividades de capacitação com escopo mais curto e complexidade menor do que a iniciativa levada a cabo no Alto Rio Negro. Ou seja, consideramos factível a oferta de cursos curtos voltados para o controle de agravos específicos de doenças vetoriais, monitoramento de agravos imunopreveníveis, vigilância alimentar e nutricional e outros temas que possam ser extraídos da matriz curricular e efetivados mediante o uso de estratégias pedagógicas e materiais instrucionais elaborados no curso rionegrino. Sem dúvida, tais iniciativas podem ampliar a aplicabilidade da proposta do CTACIS com bastante chance de sucesso, ainda que fiquem enfraquecidos os aspectos políticos e socioambientais contidos na proposta original.

Entretanto, cada conjuntura política tem sua própria dinâmica. No caso do estado do Amazonas, a ensinagem freiriana produzida no CTACIS sustenta o projeto QualificaSUS, dedicado à capacitação de cinco mil ACS nos 62 municípios do estado, o qual está em fase de implantação pelo Instituto Leônidas \& Maria Deane, unidade da Fiocruz em Manaus. Mais pragmático e menos ambicioso que o CTACIS, o projeto QualificaSUS 
adapta temas, conteúdos e materiais educativos concebidos no curso do Alto Rio Negro, com o objetivo de ofertar cem turmas de cursos de curta duração para ACS não indígenas atuantes em áreas rurais do Amazonas. O programa está começando e não dispõe ainda de produtos que permitam avaliação de processo ou de resultados. Porém, a escolha do CTACIS como eixo guia para a implantação de um novo processo de ensino-aprendizagem já é um indicador de replicabilidade do curso rio-negrino a outros contextos e realidades.

Neste livro somente se relatou uma parte da experiência formativa no Alto Rio Negro. Há ainda um amplo material inédito que versa sobre outros temas não incluídos aqui por limitação de espaço e que deverá ser objeto de futuras publicações dos autores deste livro.

As atribuições do AIS desenvolvidas no curso CTACIS foram sistematizadas de acordo com cada eixo formador e estão dispostas no Quadro 12.

\section{Quadro 12 - Atribuições do AIS em APS nos DSEls construído no CTACIS}

\begin{tabular}{|c|c|}
\hline Atribuições do AIS & Atividades sugeridas \\
\hline \multirow{6}{*}{$\begin{array}{l}\text { Organização } \\
\text { do processo de } \\
\text { trabalho segundo } \\
\text { princípios da APS }\end{array}$} & $\begin{array}{l}\text { Delimitar seu território de atuação e reconhecer a população sob sua } \\
\text { responsabilidade. }\end{array}$ \\
\hline & $\begin{array}{l}\text { Identificar os grupos e territórios mais vulneráveis e suas distintas } \\
\text { necessidades de saúde. }\end{array}$ \\
\hline & $\begin{array}{l}\text { Planejar e executar visitas domiciliares para conhecer as condições de vida, } \\
\text { a situação de saúde e as necessidades de atenção das famílias sob seus } \\
\text { cuidados. }\end{array}$ \\
\hline & $\begin{array}{l}\text { Desenvolver ações de promoção da saúde, prevenção das doenças e ofertar } \\
\text { cuidados, segundo seu perfil de competências. }\end{array}$ \\
\hline & $\begin{array}{l}\text { Estimular a participação das famílias no planejamento, execução e avaliação } \\
\text { das ações de saúde. }\end{array}$ \\
\hline & $\begin{array}{l}\text { Promover o acompanhamento contínuo e longitudinal de pessoas e famílias } \\
\text { sob cuidado, buscando meios para garantir o acesso aos demais níveis de } \\
\text { atenção. }\end{array}$ \\
\hline \multirow{3}{*}{$\begin{array}{l}\text { Elaboração de } \\
\text { diagnóstico } \\
\text { comunitário para } \\
\text { subsidiar o trabalho } \\
\text { da Emsi }\end{array}$} & $\begin{array}{l}\text { Elaborar mapas comunitários com localização de domicílios, de recursos } \\
\text { comunitários para produção da subsistência, lazer e outras atividades } \\
\text { comunais, além da identificação de locais de risco. }\end{array}$ \\
\hline & $\begin{array}{l}\text { Fazer levantamento populacional da comunidade e elaborar pirâmide } \\
\text { demográfica. }\end{array}$ \\
\hline & $\begin{array}{l}\text { Aplicar questionário para levantamento da situação socioeconômica das } \\
\text { famílias da comunidade. }\end{array}$ \\
\hline
\end{tabular}




\section{Quadro 12 - Atribuições do AIS em APS nos DSEls construído no CTACIS (continuação)}

\begin{tabular}{|c|c|}
\hline Atribuições do AIS & Atividades sugeridas \\
\hline \multirow{4}{*}{$\begin{array}{l}\text { Elaboração de } \\
\text { diagnóstico } \\
\text { comunitário para } \\
\text { subsidiar o trabalho } \\
\text { da Emsi }\end{array}$} & $\begin{array}{l}\text { Realizar levantamento e sistematização de dados sobre problemas e } \\
\text { necessidades de saúde das famílias. }\end{array}$ \\
\hline & $\begin{array}{l}\text { Fazer levantamento e registro sobre doenças e cuidados tradicionais } \\
\text { adotados na comunidade. }\end{array}$ \\
\hline & $\begin{array}{l}\text { Fazer levantamento e registro sobre a história da comunidade e relações de } \\
\text { contato interétnico, identificando suas repercussões nos modos de vida das } \\
\text { famílias, quando pertinente. }\end{array}$ \\
\hline & $\begin{array}{l}\text { Identificar os especialistas tradicionais que vivem no território indígena em } \\
\text { sua área de abrangência. }\end{array}$ \\
\hline \multirow{5}{*}{$\begin{array}{l}\text { Realizar o } \\
\text { planejamento das } \\
\text { atividades do AIS } \\
\text { em conjunto com } \\
\text { as comunidades e } \\
\text { a Emsi }\end{array}$} & $\begin{array}{l}\text { Realizar regularmente o diagnóstico comunitário no intuito de analisar a } \\
\text { dinâmica do perfil populacional e a ocorrência dos principais problemas de } \\
\text { saúde. }\end{array}$ \\
\hline & $\begin{array}{l}\text { Discutir com lideranças e comunidades os resultados e obter o diagnóstico } \\
\text { comunitário para estabelecer prioridades para a atuação do AIS. }\end{array}$ \\
\hline & $\begin{array}{l}\text { Organizar o plano de trabalho do AIS na comunidade, definindo problemas } \\
\text { prioritários, ações programadas, estratégias de alcance de resultados e } \\
\text { prazos para realização. }\end{array}$ \\
\hline & $\begin{array}{l}\text { Apresentar para lideranças e o restante da Emsi o planejamento do trabalho } \\
\text { do AIS e seu desenvolvimento. }\end{array}$ \\
\hline & $\begin{array}{l}\text { Avaliar junto com a comunidade e o restante da Emsi o desenvolvimento do } \\
\text { plano de ação dos AIS. }\end{array}$ \\
\hline \multirow{6}{*}{ Controle social } & $\begin{array}{l}\text { Conhecer a atuação da organização indígena da sua região e participar de } \\
\text { suas atividades desenvolvendo propostas voltadas para a melhoria da saúde. }\end{array}$ \\
\hline & $\begin{array}{l}\text { Participar das reuniões e atividades comunitárias, dos conselhos locais de } \\
\text { saúde e de associações de base local, apresentando dados sobre a situação } \\
\text { de saúde de sua área de abrangência e propondo ações de desenvolvimento } \\
\text { sustentável, melhoria da alimentação e do saneamento das comunidades. }\end{array}$ \\
\hline & $\begin{array}{l}\text { Acompanhar reuniões e outras atividades dos Conselhos Distritais de Saúde } \\
\text { e Conferências Nacionais de Saúde Indígena. }\end{array}$ \\
\hline & $\begin{array}{l}\text { Realizar, na comunidade, debates sobre as políticas de saúde e de saúde } \\
\text { indígena e atividades de controle social na sua região. }\end{array}$ \\
\hline & $\begin{array}{l}\text { Esclarecer os moradores sobre a política de saúde indígena, planejamento } \\
\text { anual e ações programadas para os serviços de saúde na área de abrangência } \\
\text { do DSEI. }\end{array}$ \\
\hline & $\begin{array}{l}\text { Conhecer as políticas sociais inclusivas existentes no seu território, visando } \\
\text { à divulgação e ao fortalecimento. }\end{array}$ \\
\hline
\end{tabular}




\section{Quadro 12 - Atribuições do AIS em APS nos DSEls construído no CTACIS (continuação)}

\begin{tabular}{|c|c|}
\hline Atribuições do AIS & Atividades sugeridas \\
\hline \multirow{9}{*}{$\begin{array}{l}\text { Vigilância alimentar } \\
\text { e nutricional no } \\
\text { território }\end{array}$} & $\begin{array}{l}\text { Identificar os principais alimentos consumidos no território, classificando-os } \\
\text { em alimentos coletados/produzidos e alimentos comprados (processados e } \\
\text { ultraprocessados). }\end{array}$ \\
\hline & $\begin{array}{l}\text { Levantar e registrar a classificação indígena dos alimentos, identificando } \\
\text { aqueles que as famílias considerem perigosos. }\end{array}$ \\
\hline & $\begin{array}{l}\text { Identificar os cuidados alimentares (incluindo a amamentação e cuidados } \\
\text { tradicionais) dirigidos às crianças menores de } 5 \text { anos. }\end{array}$ \\
\hline & $\begin{array}{l}\text { Levantar os itens consumidos nas refeições familiares, identificando o uso } \\
\text { de alimentos que geram risco à saúde. }\end{array}$ \\
\hline & $\begin{array}{l}\text { Discutir sobre transição alimentar e segurança alimentar nas reuniões } \\
\text { comunitárias, apontando os riscos do consumo de alimentos processados e } \\
\text { ultraprocessados. }\end{array}$ \\
\hline & $\begin{array}{l}\text { Realizar e registrar o acompanhamento nutricional das crianças de } 0 \text { a } \\
5 \text { anos e das mulheres grávidas, por meio de técnicas antropométricas } \\
\text { (pesagem, tomada de medidas), cálculo do IMC e classificação de risco } \\
\text { nutricional. }\end{array}$ \\
\hline & $\begin{array}{l}\text { Identificar e registrar os principais problemas nutricionais e transtornos } \\
\text { associados que ocorram na comunidade, abrangendo, pelo menos: baixo } \\
\text { peso ao nascer, desnutrição, sobrepeso/obesidade, diarreia, desidratação } \\
\text { e anemia. Realizar condutas corretivas no seu perfil de competências, } \\
\text { quando necessário. }\end{array}$ \\
\hline & $\begin{array}{l}\text { Desenvolver estratégias de monitoramento da situação alimentar e } \\
\text { nutricional na comunidade. }\end{array}$ \\
\hline & $\begin{array}{l}\text { Conhecer o Sisvan, realizar monitoramento nutricional regular e preencher } \\
\text { mapa diário do Sisvan. }\end{array}$ \\
\hline \multirow{5}{*}{$\begin{array}{l}\text { Promoção da saúde } \\
\text { da criança indígena }\end{array}$} & $\begin{array}{l}\text { Conhecer e valorizar os cuidados tradicionais para preservar a saúde das } \\
\text { crianças. }\end{array}$ \\
\hline & Realizar visita domiciliar das crianças recém-nascidas para: \\
\hline & - verificar e registrar peso, comprimento e perímetro encefálico; \\
\hline & • preencher Declaração de Nascido Vivo; \\
\hline & $\begin{array}{l}\text { - verificar coto umbilical e orientar sobre os cuidados com coto umbilical } \\
\text { durante o primeiro mês, principalmente para ver se há pus ou vermelhidão } \\
\text { na pele ao redor, notificando o polo-base, quando necessário; } \\
\text { - orientar sobre a importância da amamentação exclusiva até seis meses; } \\
\text { - orientar sobre a caderneta da criança e o calendário vacinal a ser seguido; e } \\
\text { - orientar sobre a higiene oral da criança durante a amamentação. }\end{array}$ \\
\hline
\end{tabular}




\section{Quadro 12 - Atribuições do AIS em APS nos DSEls construído no CTACIS (continuação)}

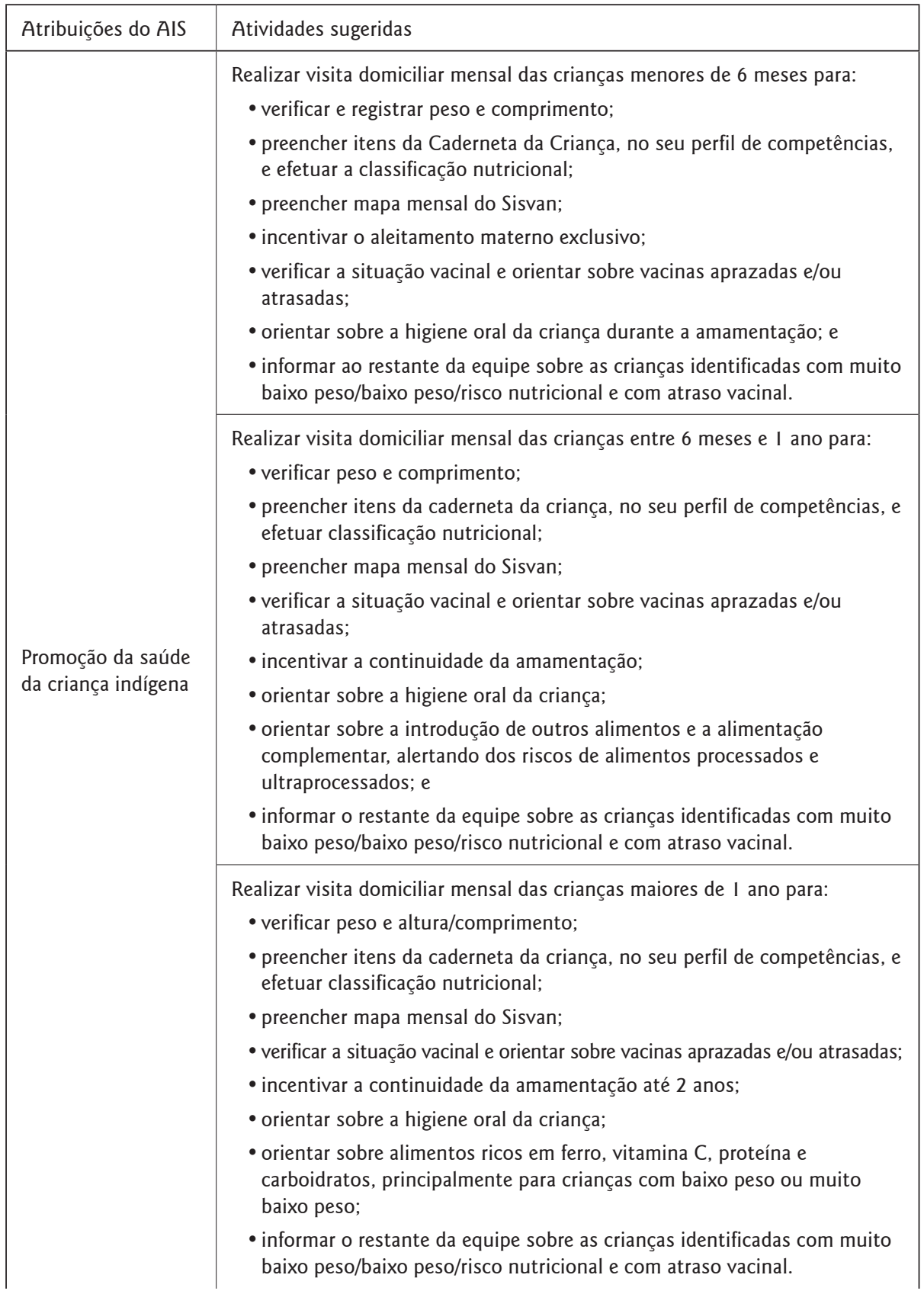




\section{Quadro 12 - Atribuições do AIS em APS nos DSEls construído no CTACIS (continuação)}

\begin{tabular}{|c|c|}
\hline Atribuições do AIS & Atividades sugeridas \\
\hline \multirow{9}{*}{$\begin{array}{l}\text { Promoção da saúde } \\
\text { da criança indígena }\end{array}$} & $\begin{array}{l}\text { Quando identificar uma criança com queixas ou em casos de demanda } \\
\text { trazida pela família: } \\
\text { • verificar sinais vitais (temperatura, frequência respiratória, pulso); } \\
\text { • realizar a classificação de caso e condutas, segundo protocolos do } \\
\text { AIDPI (MS); } \\
\text { • verificar condição de hidratação, classificar desidratação quando } \\
\text { existente e instituir tratamento de reidratação oral, se necessário; } \\
\text { - informar ao polo-base e sede DSEl sobre os casos graves e em } \\
\text { observação e encaminhar; } \\
\text { - solicitar a caderneta da criança para verificar a classificação nutricional e } \\
\text { situação vacinal; e } \\
\text { • em caso de comprometimento nutricional verificar o peso e altura/ } \\
\text { comprimento e reavaliar classificação nutricional. }\end{array}$ \\
\hline & $\begin{array}{l}\text { Desenvolver atividades comunitárias para a prevenção de doenças e } \\
\text { promoção da saúde das crianças como: }\end{array}$ \\
\hline & $\begin{array}{l}\text { - discutir a situação de saúde das crianças, identificando os fatores de } \\
\text { risco, situações de vulnerabilidade e problemas de saúde identificados } \\
\text { pelo AIS, as famílias e outros profissionais da equipe; }\end{array}$ \\
\hline & $\begin{array}{l}\text { - discutir a situação alimentar das crianças e alternativas para melhoria } \\
\text { da alimentação. Incentivar o aleitamento materno e o consumo de } \\
\text { alimentos ricos em ferro, vitamina C, proteínas e carboidratos; }\end{array}$ \\
\hline & $\begin{array}{l}\text { - discutir a vacinação, sua importância, o calendário vacinal e a } \\
\text { participação da comunidade nas ações de vacinação. Apresentar os } \\
\text { resultados das ações de vacinação realizadas na comunidade; }\end{array}$ \\
\hline & $\begin{array}{l}\text { - orientar sobre a higienização oral das crianças e realizar atividades } \\
\text { coletivas de escovação; e }\end{array}$ \\
\hline & $\begin{array}{l}\text { - caso ocorra a epidemia de alguma doença (como gripe ou diarreia/ } \\
\text { desidratação), discutir com a comunidade a tomada de medidas } \\
\text { necessárias para lidar com o problema. }\end{array}$ \\
\hline & $\begin{array}{l}\text { Manter atualizado o registro de crianças menores de } 5 \text { anos acompanhadas, } \\
\text { com destaque para informações nutricionais e situação vacinal. Efetuar } \\
\text { registro específico para acompanhamento de crianças em tratamento na } \\
\text { cidade. }\end{array}$ \\
\hline & $\begin{array}{l}\text { Notificar a Emsi e o polo-base dos casos de morte de crianças e participar } \\
\text { do processo de investigação do óbito. }\end{array}$ \\
\hline $\begin{array}{l}\text { Promoção da saúde } \\
\text { da mulher indígena }\end{array}$ & $\begin{array}{l}\text { Identificar e registrar informações sobre as mulheres grávidas, puérperas } \\
\text { e em idade fértil da comunidade e manter tais dados atualizados no } \\
\text { Formulário de Acompanhamento da Saúde da Mulher Indígena pelo AIS. }\end{array}$ \\
\hline
\end{tabular}




\section{Quadro 12 - Atribuições do AIS em APS nos DSEls construído no CTACIS (continuação)}

\begin{tabular}{|c|c|}
\hline Atribuições do AIS & Atividades sugeridas \\
\hline \multirow{16}{*}{$\begin{array}{l}\text { Promoção da saúde } \\
\text { da mulher indígena }\end{array}$} & Identificar as mulheres grávidas e realizar visita domiciliar mensal para: \\
\hline & - pesar, medir altura, aferir PA, pulso e anotar esses resultados; \\
\hline & $\begin{array}{l}\text { - verificar a existência de queixas sugestivas de doença e/ou intercorrência } \\
\text { na gravidez ou no puerpério; se houver queixas comunicar ao polo-base; }\end{array}$ \\
\hline & $\begin{array}{l}\text { - revisar caderneta da gestante e/ou cartão de vacina, com prioridade para } \\
\text { os seguintes itens: DUM, DPP, número de consultas de APN, número de } \\
\text { consultas de puerpério (se for o caso) e doses de vacina já aplicadas; }\end{array}$ \\
\hline & $\begin{array}{l}\text { - avaliar a situação vacinal da gestante e, caso existente, informar as } \\
\text { equipes sobre necessidades de vacinação; }\end{array}$ \\
\hline & $\begin{array}{l}\text { - realizar a avaliação nutricional da gestante, preenchimento dos } \\
\text { formulários do Sisvan e efetuar orientação alimentar; }\end{array}$ \\
\hline & $\begin{array}{l}\text { - verificar o uso de suplemento de sulfato ferroso e orientar sobre uso do } \\
\text { medicamento e sobre alimentos ricos em ferro; }\end{array}$ \\
\hline & $\begin{array}{l}\text { - realizar o registro mensais das informações de acompanhamento da } \\
\text { gestante no Formulário de Acompanhamento da Saúde da Mulher } \\
\text { Indígena pelo AIS, mês a mês; }\end{array}$ \\
\hline & $\begin{array}{l}\text { - conversar e orientar sobre cuidados tradicionais com a mulher na } \\
\text { gravidez; }\end{array}$ \\
\hline & $\begin{array}{l}\text { - se a gestante ou puérpera tiver queixas de sangramento, corrimento, dor } \\
\text { ou outros sintomas deve informar o restante da Emsi. }\end{array}$ \\
\hline & $\begin{array}{l}\text { Discutir na comunidade sobre a importância do fortalecimento dos cuidados } \\
\text { tradicionais no parto e orientar sobre as indicações específicas de parto } \\
\text { hospitalar. }\end{array}$ \\
\hline & $\begin{array}{l}\text { Caso a comunidade considere adequado, conversar com a mulher e/ } \\
\text { ou esposo sobre o uso de métodos contraceptivos para orientações, } \\
\text { encaminhamento à equipe e acompanhamento do uso de anticoncepcionais } \\
\text { prescritos. }\end{array}$ \\
\hline & $\begin{array}{l}\text { Realizar o acompanhamento do preventivo do colo uterino (PCCU) das } \\
\text { mulheres na faixa etária entre } 25 \text { a } 65 \text { anos, por meio de: }\end{array}$ \\
\hline & $\begin{array}{l}\text { - atividades educativas para as mulheres e familiares sobre realização do } \\
\text { exame do PCCU e sua importância; }\end{array}$ \\
\hline & $\begin{array}{l}\text { - acompanhamento da frequência da realização do PCCU, mantendo um } \\
\text { registro atualizado das datas de coleta, aprazamento e das mulheres com } \\
\text { exames em atraso. Informar os outros membros da equipe sobre exames } \\
\text { em atraso; e }\end{array}$ \\
\hline & $\begin{array}{l}\text { - identificação e encaminhamento, para os outros membros da equipe, das } \\
\text { mulheres com necessidade de realizar exames do PCCU. }\end{array}$ \\
\hline
\end{tabular}




\section{Quadro 12 - Atribuições do AIS em APS nos DSEls construído no CTACIS (continuação)}

\begin{tabular}{|c|c|}
\hline Atribuições do AIS & Atividades sugeridas \\
\hline \multirow{6}{*}{$\begin{array}{l}\text { Promoção da saúde } \\
\text { da mulher indígena }\end{array}$} & $\begin{array}{l}\text { Identificar mulheres com queixas de corrimento, de dor ou outros sintomas } \\
\text { de doenças ginecológicas, para encaminhamento ao polo-base. }\end{array}$ \\
\hline & $\begin{array}{l}\text { Desenvolver atividades comunitárias de educação em saúde sobre: } \\
\text { - importância e rotinas de pré-natal e dos cuidados com as mulheres } \\
\text { grávidas; }\end{array}$ \\
\hline & $\begin{array}{l}\text { • importância da higienização oral das mulheres e, em particular, das } \\
\text { grávidas; }\end{array}$ \\
\hline & $\begin{array}{l}\text { - discutir a situação nutricional encontrada na população de grávidas da } \\
\text { comunidade; e }\end{array}$ \\
\hline & - orientar sobre alimentação saudável. \\
\hline & $\begin{array}{l}\text { Apresentar seus registros e resultados do acompanhamento das mulheres } \\
\text { grávidas aos outros membros da Emsi. }\end{array}$ \\
\hline \multirow{10}{*}{$\begin{array}{l}\text { Prevenção e controle } \\
\text { de portadores } \\
\text { de hipertensão e } \\
\text { diabetes* }\end{array}$} & $\begin{array}{l}\text { Realizar atividades educativas individuais e coletivas sobre doenças crônicas } \\
\text { como diabetes tipos I e Il e hipertensão, seus principais fatores de risco e } \\
\text { medidas de prevenção. }\end{array}$ \\
\hline & $\begin{array}{l}\text { Realizar e/ou participar de atividades individuais e coletivas para } \\
\text { rastreamento de hipertensão e diabetes tipo Il em maiores de } 18 \text { anos, com } \\
\text { aferição de PA, dosagem de glicemia e classificação nutricional segundo IMC. }\end{array}$ \\
\hline & $\begin{array}{l}\text { Realizar visita domiciliar para acompanhamento das pessoas com medidas } \\
\text { alteradas de glicemia e hipertensão para que sejam orientadas sobre } \\
\text { fatores de risco, tratamento não medicamentoso e encaminhamento para } \\
\text { confirmação diagnóstica, quando necessário; }\end{array}$ \\
\hline & $\begin{array}{l}\text { As pessoas com diagnóstico confirmado de diabetes e hipertensão devem } \\
\text { ser acompanhadas para: }\end{array}$ \\
\hline & $\begin{array}{l}\text { - medir PA semanalmente e manter registro atualizado dos resultados para } \\
\text { apresentá-los aos outros membros da EMSI; }\end{array}$ \\
\hline & $\begin{array}{l}\text { - verificar periodicamente a glicemia capilar e manter registro atualizado } \\
\text { dos resultados para apresentá-los aos outros membros da EMSI; }\end{array}$ \\
\hline & $\begin{array}{l}\text { - realizar acompanhamento e orientação sobre alimentação, atividades } \\
\text { físicas, consumo de álcool e tabaco; }\end{array}$ \\
\hline & $\begin{array}{l}\text { - acompanhar o tratamento medicamentoso de pacientes cadastrados } \\
\text { no HIPERDIA, observando e orientando sobre posologia prescrita pelo } \\
\text { médico, regularidade de uso, data de vencimento dos medicamentos e } \\
\text { necessidade de renovação da prescrição. Observar e registrar possíveis } \\
\text { efeitos colaterais, bem como as dúvidas dos pacientes e prover } \\
\text { informações regulares para os outros membros da EMSI; }\end{array}$ \\
\hline & $\begin{array}{l}\text { - medir mensalmente o peso e altura, calcular IMC, e orientar controle ou } \\
\text { perda de peso, nos casos de sobrepeso e obesidade; }\end{array}$ \\
\hline & - verificar uso de tratamento tradicional e seus efeitos; \\
\hline
\end{tabular}




\section{Quadro 12 - Atribuições do AIS em APS nos DSEls construído no CTACIS (continuação)}

\begin{tabular}{|c|c|}
\hline Atribuições do AIS & Atividades sugeridas \\
\hline \multirow{3}{*}{$\begin{array}{l}\text { Prevenção e controle } \\
\text { de portadores } \\
\text { de hipertensão e } \\
\text { diabetes* }\end{array}$} & $\begin{array}{l}\text { - revisar periodicamente os pés e feridas em pessoas diabéticas, efetuando } \\
\text { orientações quando necessário. Na ocorrência desses agravos, informar } \\
\text { outros membros da EMSI; } \\
\text { - observar sinais e sintomas de alerta de crise hipertensiva, orientando } \\
\text { sobre as principais medidas a serem tomadas. Informar imediatamente } \\
\text { os outros membros da EMSI sobre esses eventos; frente a sinais de alerta } \\
\text { solicitar remoção; }\end{array}$ \\
\hline & $\begin{array}{l}\text { Manter um registro regular das informações sobre o rastreamento e } \\
\text { acompanhamento de suspeitos e casos confirmados de hipertensão e } \\
\text { diabetes. Apresentá-los mensalmente aos outros membros da Emsi; }\end{array}$ \\
\hline & $\begin{array}{l}\text { Realizar discussões comunitárias sobre as medidas de prevenção e controle } \\
\text { de diabetes e hipertensão, qualidade e quantidade de alimentos e refletir } \\
\text { sobre o processo de transição alimentar e segurança alimentar; }\end{array}$ \\
\hline \multirow{8}{*}{$\begin{array}{l}\text { Vigilância e controle } \\
\text { da malária* }\end{array}$} & $\begin{array}{l}\text { Realizar atividade educativa individual e coletiva sobre a prevenção e controle } \\
\text { da malária; }\end{array}$ \\
\hline & $\begin{array}{l}\text { Nas comunidades que possuem casos de malária, mas foram infectadas fora } \\
\text { de sua comunidade, o AIS pode realizar: }\end{array}$ \\
\hline & $\begin{array}{l}\text { - atividades educativas sobre o controle de vetor e medidas de prevenção } \\
\text { de malária a serem adotadas quando as famílias viajarem para área de } \\
\text { risco de malária. Orientar também sobre sinais, sintomas e tratamento; }\end{array}$ \\
\hline & $\begin{array}{l}\text { - organizar periodicamente mutirões comunitários para busca de } \\
\text { criadouros de mosquitos nas áreas próximas das moradias e locais mais } \\
\text { frequentados pela comunidade, como roças e outros. Realizar eliminação } \\
\text { de criadouros, se necessário; }\end{array}$ \\
\hline & $\begin{array}{l}\text { - acompanhar as pessoas que retornaram de viagem a áreas com } \\
\text { transmissão de malária, efetuando identificação precoce de sintomáticos. } \\
\text { Para estes realizar teste rápido e exame de gota espessa. Na positividade } \\
\text { do teste rápido e/ou do resultado da lâmina lida pelo polo-base, iniciar } \\
\text { tratamento, seguindo protocolo de controle da malária. Se necessário, } \\
\text { encaminhar; }\end{array}$ \\
\hline & $\begin{array}{l}\text { - para os casos confirmados preencher boletins de notificação, enviar } \\
\text { lâmina para revisão, solicitar kit completo de tratamento e efetuar } \\
\text { rastreamento dos demais familiares e/ou companheiros de viagem. Findo } \\
\text { o tratamento, coletar lâmina de verificação de cura (LVC) e enviar para } \\
\text { avaliação no polo-base. }\end{array}$ \\
\hline & $\begin{array}{l}\text { Nas comunidades com casos frequentes de malária e/ou com transmissão } \\
\text { autóctone o AIS deve: }\end{array}$ \\
\hline & $\begin{array}{l}\text { - realizar atividades educativas regulares sobre o controle de vetor (manejo } \\
\text { ambiental), medidas de prevenção de malária e orientação sobre sinais } \\
\text { precoces da doença; }\end{array}$ \\
\hline
\end{tabular}




\section{Quadro 12 - Atribuições do AIS em APS nos DSEls construído no CTACIS (continuação)}

\begin{tabular}{|c|c|}
\hline Atribuições do AIS & Atividades sugeridas \\
\hline \multirow{7}{*}{$\begin{array}{l}\text { Vigilância e controle } \\
\text { da malária* }\end{array}$} & $\begin{array}{l}\text { - realizar mutirões comunitários regulares para identificação e erradicação } \\
\text { de criadouros na comunidade e/ou locais frequentados como as roças } \\
\text { (em uso e roças velhas), locais de banho e outros; }\end{array}$ \\
\hline & $\begin{array}{l}\text { - orientar para a tomada de medidas de prevenção como uso de telas nas } \\
\text { janelas e uso de mosquiteiros impregnados; }\end{array}$ \\
\hline & $\begin{array}{l}\text { - realizar busca ativa de casos de malária por meio de teste rápido e } \\
\text { coleta de lâmina de gota espessa em sintomáticos febris e/ou contatos } \\
\text { familiares. Na positividade do teste rápido e/ou do resultado da lâmina } \\
\text { lida pelo polo-base, iniciar tratamento, seguindo protocolo de controle } \\
\text { da malária. Se necessário, encaminhar; }\end{array}$ \\
\hline & $\begin{array}{l}\text { - para os casos confirmados preencher boletins de notificação, enviar } \\
\text { lâmina para revisão, solicitar kit completo de tratamento e efetuar } \\
\text { rastreamento dos demais familiares e/ou companheiros de viagem. Findo } \\
\text { o tratamento, coletar lâmina de verificação de cura (LVC) e enviar para } \\
\text { avaliação no polo-base. }\end{array}$ \\
\hline & $\begin{array}{l}\text { - realizar ou participar de inquéritos, estendendo a busca ativa de caso } \\
\text { entre os assintomáticos. Tais atividades deverão ser planejadas e } \\
\text { incluídas nos planos de ação do polo-base, em acordo com os outros } \\
\text { membros da EMSI e órgãos de vigilância epidemiológica. Nesses casos } \\
\text { preencher a "Ficha de inquérito para identificação de malária". }\end{array}$ \\
\hline & $\begin{array}{l}\text { Manter um controle mensal do número de lâminas de gota espessa, testes } \\
\text { de malária realizados e casos positivos; }\end{array}$ \\
\hline & $\begin{array}{l}\text { Preencher os formulários disponibilizados pelo Sistema de Informação de } \\
\text { Vigilância Epidemiológica; }\end{array}$ \\
\hline \multirow{4}{*}{$\begin{array}{l}\text { Apoio ao controle } \\
\text { da hanseníase* }\end{array}$} & $\begin{array}{l}\text { Desenvolver ações educativas e de mobilização envolvendo a comunidade } \\
\text { (escolas, conselhos de saúde, associações de moradores, etc.), divulgando } \\
\text { a importância do autoexame para identificação de manchas suspeitas de } \\
\text { hanseníase e de combate ao preconceito; }\end{array}$ \\
\hline & $\begin{array}{l}\text { Identificar sinais e sintomas da hanseníase e encaminhar os casos suspeitos } \\
\text { para médico ou enfermeiro do DSEl; }\end{array}$ \\
\hline & $\begin{array}{l}\text { Acompanhar mensalmente os portadores de hanseníase, em tratamento e } \\
\text { orientá-los; }\end{array}$ \\
\hline & $\begin{array}{l}\text { Encaminhar contatos intradomiciliares para avaliação na unidade de saúde e } \\
\text { estimulá-los a realizar o autoexame, mesmo depois da avaliação; }\end{array}$ \\
\hline $\begin{array}{l}\text { Prevenção e controle } \\
\text { das infecções } \\
\text { sexualmente } \\
\text { transmissíveis* }\end{array}$ & $\begin{array}{l}\text { Discutir com as famílias e lideranças sobre a pertinência de realizar, na } \\
\text { comunidade, ações de prevenção das IST e uso de preservativos; }\end{array}$ \\
\hline
\end{tabular}




\section{Quadro 12 - Atribuições do AIS em APS nos DSEls construído no CTACIS (continuação)}

\begin{tabular}{|c|c|}
\hline Atribuições do AIS & Atividades sugeridas \\
\hline \multirow{4}{*}{$\begin{array}{l}\text { Prevenção e controle } \\
\text { das infecções } \\
\text { sexualmente } \\
\text { transmissíveis* }\end{array}$} & $\begin{array}{l}\text { Desenvolver atividades informativo-educativas individuais e coletivas, com o } \\
\text { objetivo de informar e motivar a população para a prevenção de IST; }\end{array}$ \\
\hline & $\begin{array}{l}\text { Verificar se as gestantes sob acompanhamento pré-natal realizaram testes } \\
\text { para HIV, hepatite B e sífilis; revisar caderneta de gestante, verificando } \\
\text { necessidade de atualização de doses de vacina contra hepatite B; }\end{array}$ \\
\hline & $\begin{array}{l}\text { Acolher as pessoas com queixas sugestivas de IST e encaminhá-las para } \\
\text { avaliação médica; }\end{array}$ \\
\hline & $\begin{array}{l}\text { Orientar sobre uso de preservativo e efetuar a distribuição deles, quando } \\
\text { disponíveis; }\end{array}$ \\
\hline \multirow{13}{*}{$\begin{array}{l}\text { Controle e } \\
\text { acompanhamento } \\
\text { do tratamento das } \\
\text { doenças diarreicas } \\
\text { agudas }\end{array}$} & $\begin{array}{l}\text { Realizar atividades coletivas voltadas para a saúde ambiental da comunidade } \\
\text { e para aprimorar a gestão dos dejetos; }\end{array}$ \\
\hline & $\begin{array}{l}\text { Realizar atividades individuais e/ou coletivas educativas sobre os modos } \\
\text { de transmissão de diarreia agudas, medidas de prevenção e orientações de } \\
\text { tratamento; }\end{array}$ \\
\hline & Identificar as crianças com diarreia para: \\
\hline & - realizar a classificação do estado de desidratação; \\
\hline & - definir o plano de reidratação $(A, B$ ou $C)$ \\
\hline & $\begin{array}{l}\text { - instituir e supervisionar o tratamento de reidratação das crianças com } \\
\text { desidratação leve. Para os demais casos acionar o polo-base; }\end{array}$ \\
\hline & $\begin{array}{l}\text { - revisar os dados disponíveis sobre estado nutricional e/ou transtornos } \\
\text { associados na criança com diarreia, identificando associação de agravos } \\
\text { que adicionam fatores de risco à criança desidratada; }\end{array}$ \\
\hline & $\begin{array}{l}\text { - orientar sobre medidas gerais de alimentação e cuidados com a } \\
\text { população infantil; }\end{array}$ \\
\hline & $\begin{array}{l}\text { - orientar familiares sobre sinais de desidratação e estratégias de } \\
\text { reidratação oral; }\end{array}$ \\
\hline & $\begin{array}{l}\text { - encaminhar, em regime de urgência, as crianças com desidratação grave. } \\
\text { Solicitar aos outros membros da Emsi orientações sobre o manejo de } \\
\text { casos de desidratação moderada; }\end{array}$ \\
\hline & $\begin{array}{l}\text { - encaminhar para avaliação as crianças com desidratação recorrente, com } \\
\text { desnutrição e outros agravos comuns na infância; }\end{array}$ \\
\hline & $\begin{array}{l}\text { Manter um registro mensal dos casos de diarreia/desidratação e apresentar } \\
\text { seus registros para o restante da Emsi; }\end{array}$ \\
\hline & $\begin{array}{l}\text { Discutir com as equipes do DSEl e os Aisan sobre a situação de saneamento } \\
\text { da comunidade, propondo medidas de aprimoramento; }\end{array}$ \\
\hline
\end{tabular}




\section{Quadro 12 - Atribuições do AIS em APS nos DSEls construído no CTACIS (continuação)}

\begin{tabular}{|c|c|}
\hline Atribuições do AIS & Atividades sugeridas \\
\hline \multirow{8}{*}{$\begin{array}{l}\text { Controle e } \\
\text { acompanhamento } \\
\text { do tratamento } \\
\text { das infecções } \\
\text { respiratórias agudas }\end{array}$} & $\begin{array}{l}\text { Realizar atividades individuais e/ou coletivas educativas sobre os modos } \\
\text { de transmissão de infecções respiratórias agudas, medidas de prevenção e } \\
\text { orientações gerais de cuidados aos portadores desses quadros; }\end{array}$ \\
\hline & $\begin{array}{l}\text { Realizar a avaliação de pessoas com sintomas de infecções respiratórias } \\
\text { agudas para: }\end{array}$ \\
\hline & $\begin{array}{l}\text { - avaliação dos sinais vitais (temperatura, frequência respiratória e } \\
\text { frequência cardíaca); }\end{array}$ \\
\hline & $\begin{array}{l}\text { - classificar a infecção respiratória aguda em DRA, síndrome gripal ou } \\
\text { suspeita de pneumonia, instituindo condutas a serem adotadas com base } \\
\text { nos resultados da classificação; }\end{array}$ \\
\hline & - orientar medidas gerais de hidratação e tratamento; \\
\hline & - encaminhar casos suspeitos de pneumonia; \\
\hline & - encaminhar os sintomáticos respiratórios crônicos para avaliação; \\
\hline & $\begin{array}{l}\text { Manter registro mensal dos casos de IRA na comunidade e discutir os dados } \\
\text { com o restante da Emsi; }\end{array}$ \\
\hline \multirow{7}{*}{$\begin{array}{l}\text { Apoio ao } \\
\text { acompanhamento } \\
\text { de sintomáticos } \\
\text { respiratórios } \\
\text { e pessoas em } \\
\text { tratamento de } \\
\text { tuberculose* }\end{array}$} & $\begin{array}{l}\text { Realizar periodicamente o rastreamento de sintomáticos respiratórios } \\
\text { crônicos; }\end{array}$ \\
\hline & Encaminhar pessoas com tosse crônica para avaliação médica; \\
\hline & Orientar sobre a forma de coleta do exame de escarro dos casos suspeitos; \\
\hline & $\begin{array}{l}\text { Realizar visita domiciliar semanal para acompanhamento dos pacientes em } \\
\text { tratamento de tuberculose, fazer orientação alimentar e supervisionar o uso } \\
\text { correto dos medicamentos; }\end{array}$ \\
\hline & $\begin{array}{l}\text { Caso esteja implantado no DSEI, realizar o Tratamento Diretamente } \\
\text { Observado (DOT); }\end{array}$ \\
\hline & $\begin{array}{l}\text { Realizar pesagem mensal dos pacientes em tratamento subsidiar reavaliação } \\
\text { da dose pelo médico; }\end{array}$ \\
\hline & $\begin{array}{l}\text { Encaminhar para avaliação os comunicantes dos casos confirmados de } \\
\text { tuberculose; }\end{array}$ \\
\hline
\end{tabular}

* Atribuições desenvolvidas no CTACIS cujo processo pedagógico não foi descrito neste livro. 